\title{
Modelling albedo and specific balance of the Greenland ice sheet: calculations for the Søndre Strømfjord transect
}

\author{
Z. ZuO AND J. Oerlemans \\ Institute for Marine and Atmospheric Research Utrecht, Utrecht University, \\ Princetonplein 5, 3584 CC, Utrecht, The Netherlands
}

\begin{abstract}
Glacio-meteorological data obtained during the Greenland Ice Margin Experiment (GIMEX) investigations in West Greenland the Sondre Stromfjord transect) have been used to test and calibrate four energy-balance/massbalance models for the ice/snow surface. The region is characterised by the development of a wide zone of low surface albedo in the course of the melting season. This zone was simulated in one of the energy-balance models by including the effect of surficial meltwater on albedo. Observed mass-balance and albedo data were used to constrain the models. Although all the models are capable of predicting the transect balance reasonably well, only the model with the meltwater-albedo coupling, is able to reproduce the observed albedo pattern and mass-balance profile along the transect. By including the feedback between surficial meltwater and albedo in the model, the sensitivity of the specific balance to changes in air temperature is found to be greatest just below the equilibrium line (in contrast to what is generally found for valley glaciers). A $1 \mathrm{~K}$ warming of the air temperature would increase the mean ablation along the transect by $0.5 \mathrm{~m}$ w.e. year ${ }^{-1}$.
\end{abstract}

\section{INTRODUCTION}

In recent years, studies have been done on the dynamic response of the Greenland ice sheet to climatic change, with emphasis on its possible contribution to sea-level rise in case of global warming (Ambach, 1979; Weidick, 1984; Braithwaite and Olesen, 1990; Huybrechts and others, 1991; Oerlemans, 1991; Van de Wal and Oerlemans, 1994). Simulation of the ice sheet by numerical models depends critically on the way in which the surface mass balance is formulated. The surface balance can be prescribed, calculated with a degree-day model (e.g. Braithwaite and Olesen, 1989; Reeh, 1991) or with an energy-balance model (e.g. Oerlemans, 1991), or taken from GCM output (Ohmura and Wild, 1995). In our view, the energybalance model is an attractive tool for simulating the surface mass balance, since the physical processes on the surface can be described fairly explicitly in the model.

Up till now, however, mass-balance models for the Greenland ice sheet, following either the degree-day (Reeh, 1991) or energy-balance approach (Oerlemans, 1991; Van de Wal and Oerlemans, 1994) have not been rigorously validated. One of the problems is the lack of representative data. Nevertheless, we feel that the data we now have available allow us to perform better model tests than those performed so far. The Sondre Stromfjord transect provides us with a good opportunity, since 4 years of mass-balance observations are now available, together with the results of two detailed meteorological experiments (GIMEX-90 and GIMEX-91; see Fig. 1 for the set-up). In the course of the work along the Sondre
Stromfjord transect, however, it has become clear that the melt physics of this part of the ice sheet are complicated. In particular, the spatial variability and temporal evolution of the albedo makes modelling difficult. This is illustrated in Figure 2 which shows the daily mean albedo as measured at sites $4-9$ (see Fig. 1 for locations), together with a snapshot of the spatial distribution of the albedo in the melting zone of central West Greenland, as derived from a NOAA-AVHRR (Advanced Very High Resolution Radiometer) image (Knap and Oerlemans, 1996). In the course of the melt season, a band of low albedo develops parallel to the ice edge, the physics of which are poorly understood. We will discuss this feature at length and try to reproduce it in one of our models.

Recently, 4 year observations of mass balance have become available (given in table in Van de Wal and others (in press); Fig. 3). Although a standard deviation can be calculated for each stake location on the basis of the interannual variability within the 4 year period, it is not clear how representative the balance profile is for the longterm (for instance, 30 year) mean. An additional problem is that the energy-balance model requires input data that are not very well known. For example, little is known about precipitation. Although regular weather observations are carried out at Sondre Stromfjord airport, it is hard to see that precipitation amounts measured there are representative for the ice-sheet sector under study. For instance, it is known that in summer significant convective precipitation occurs over the tundra but not over the ice sheet. Also, because of orographic effects considerable variation can occur on a $100 \mathrm{~km}$ scale. In spite of these and 


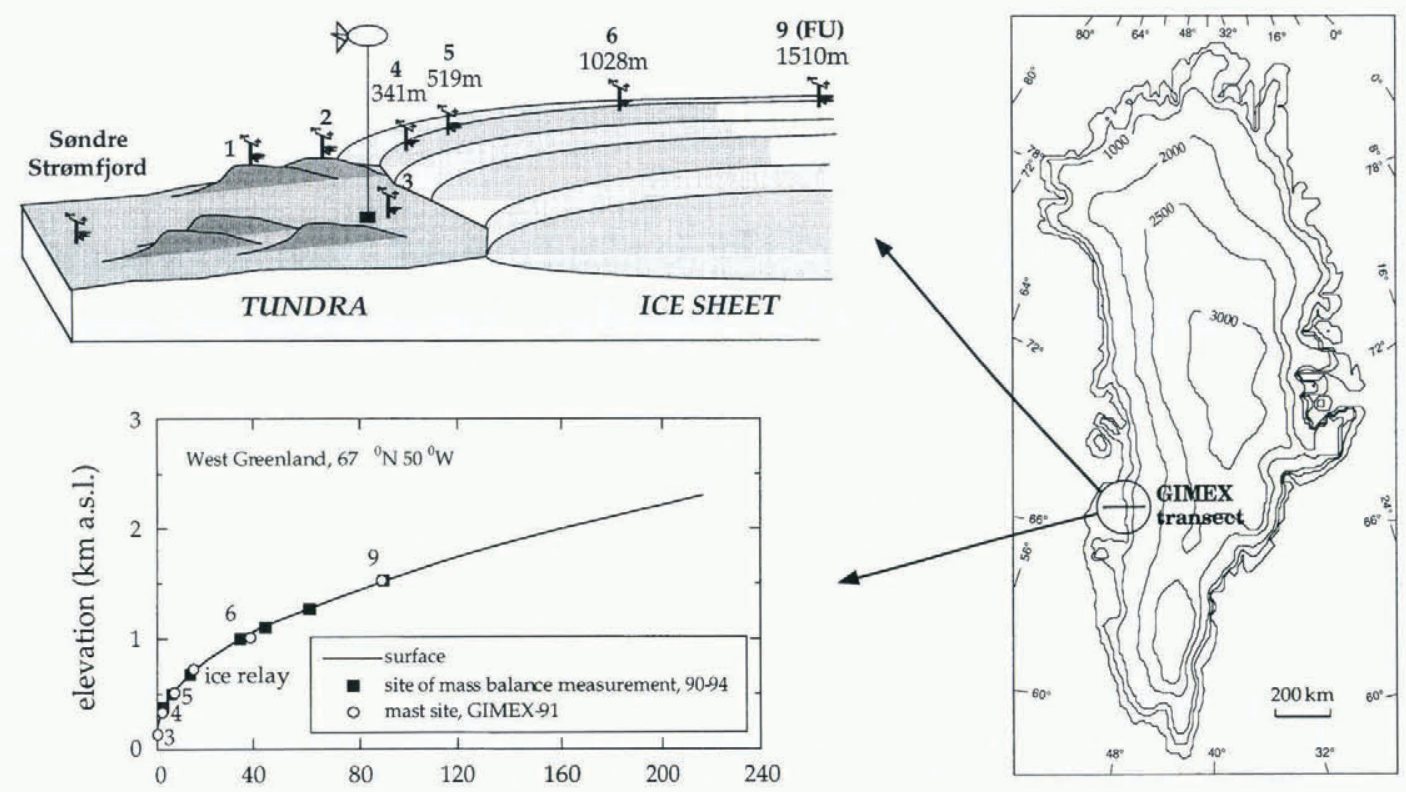

Fig. 1. The experimental set-up during GIMEX-91 and surface elevation of the "ice stations". Site 9 is the boundary-layer station of the Free University of Amsterdam.
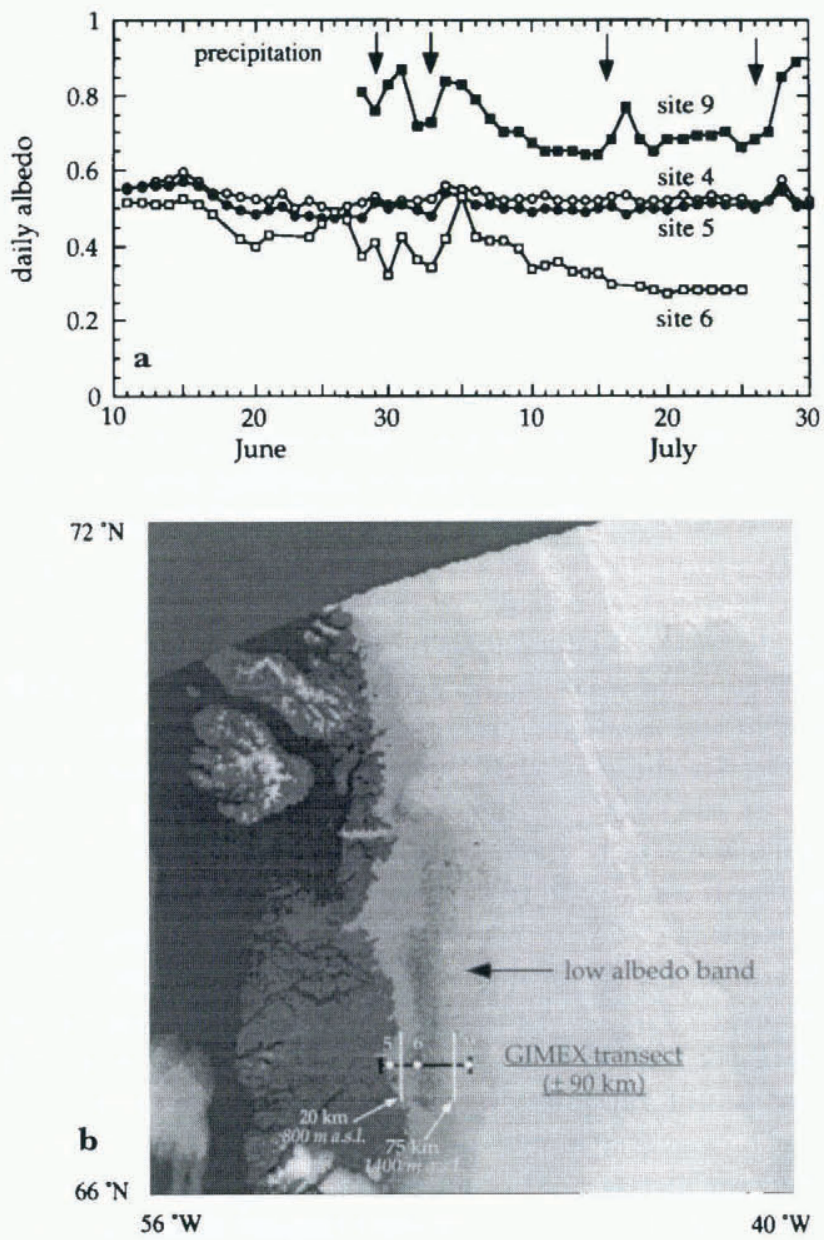

Fig. 2. (a) Daily albedo in the summer of 1991 measured during GIMEX-91. Sites as indicated in Figure 1. (b) AVHRR image (visible, channel 2) from the NOAA-11 satellite for the Sondre Stromfjord area, showing a distinct band of low albedo (20-75 km from the ice margin) on 25 July 1991. The GIMEX transect (thick black line) and the location of sites 5, 6 and 9 (filled white circles) are also shown. other complications, we thought it would be worth doing a study with an energy-balance model. Although the detailed meteorological experiments lasted for only a short time, they have nevertheless taught us a great deal about the exchange of energy between surface and atmosphere, and about altitudinal gradients along the ice-sheet surface. This puts the parameterizations used in the energy-balance model on a sounder basis.

In the following sections we will first discuss the observations made as part of the Greenland Ice Margin Experiment (GIMEX). We postulate that meltwater plays a key role in the spatial and temporal variation of the albedo. Then we describe the energy-balance model used to simulate the specific balance along the Sondre Stromfjord transect. It is based on Oerlemans (1991), but because several of the parameterizations of energy fluxes have been changed, a full description of the model is given. The changes have been made on the basis of the GIMEX experiments, and concern turbulent-exchange coefficients and the effect of clouds on the radiation balance. The treatment of the albedo is perhaps the most critical part of the study. Since the sensitivity of glacier mass balance to climate change is significantly affected by the albedo feedback, it is important to generate the albedo in the model. We have used four 'albedo models',

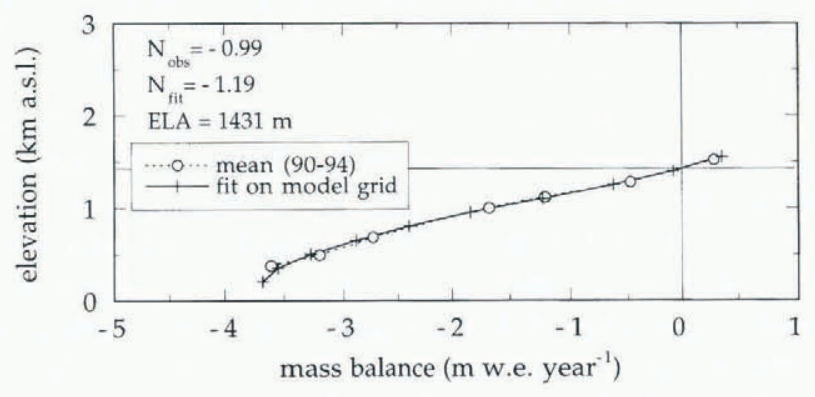

Fig. 3. Mean profile of mass-balance observations for the years 1990-94 together with the best fit to the model grid. 
one of which involves explicitly surficial meltwater. We discuss which albedo model performs best.

\section{OBSERVATIONS}

The GIMEX expeditions were carried out in the Sondre Stromfjord area, $67^{\circ} \mathrm{N}, 50^{\circ} \mathrm{W}$, West Greenland, in the summers of 1990 and 1991. During the experiments, meteorological quantities (air temperature, humidity, wind speed, wind direction, short- and long-wave radiation) were measured at several masts along a transect (the Sondre Stromfjord transect) perpendicular to the ice edge. Masts on the ice sheet stood freely on the surface. The construction consisted of a regular aluminium mast with four long legs, each at an angle of $10^{\circ}$ with the surface. Sharp pins were attached to the ends of the legs to keep the mast in place. It is estimated that the tilt of the mast was less than $2^{\circ}$ over the entire period. Data were collected via a telemetric system. Most of the time the sampling frequency for all sensors was $2 \mathrm{~min}$. Figure 1 shows the set-up of the masts during GIMEX-91 and the approximate surface elevation of the ice sheet. The GIMEX expeditions are described in detail in field reports by $\mathrm{R}$. Bintanja and others (unpublished information, 1991) and W. Boot and others (unpublished information, 1991). An overview can be found in Oerlemans and Vugts (1993).

Global radiation and short-wave reflected radiation were measured simultaneously with a Kipp CM14 pyranometer. No condensation occurred on the instruments, because of the relatively high temperature in the area during the field experiment. The precision of the upand down-facing pyranometers is within $2 \%$. A slight tilt of the instruments from the horizontal plane will introduce an additional error. However, provided the tilt is no more than a few degrees, the effect on the daily albedo is negligible (unpublished information from W. H. Knap, 1992).

We define the daily albedo $\alpha$ as the ratio of the daily totals of short-wave reflected radiation and global radiation. Figure 2a shows the daily albedo for sites 4, 5, 6 and 9 taken during a $51 \mathrm{~d}$ period (10 June-30 July 1991). The albedo on the tundra (site 3, not shown) has a rather constant value but drops slightly when precipitation occurs. Snowfall shows up very clearly in the albedo record at site 9 . The snowfall on 3-4 July causes a steep increase in the albedo at sites 6 and 9 , but the increase is not so pronounced at sites nearer the ice margin ( 4 and 5 ), probably because the precipitation there fell as rain. The characteristic daily albedo of fresh summer snow apparently is about 0.85 and declines to a value of about 0.65 in a few days. This finding is in good agreement with the measurements made by the Swiss Federal Institute of Technology (ETH-Camp) at an elevation of $1155 \mathrm{~m}$ a.s.l. at a location somewhat further north (Ohmura and others, 1992).

Near the ice margin (sites 4 and 5), the albedo remains at rather constant values of $0.50-0.55$. Apparently, the dust coming from the tundra is not sufficient to cause a significant lowering of the albedo on the ice sheet. It is not clear, however, whether this is also the case in other parts of the ice margin. Particularly striking in Figure 2a is the large decrease in the albedo at site 6 in the course of the melt season. The observed reduction is related to the abundance of meltwater in the snowpack and/or at the surface, which is typical for this zone below the equilibrium line (in this region the equilibrium line is at an elevation of about 1400 ma.s.l.). Meltwater accumulates in small pools on an irregular and bumpy surface, and patches of old snow become saturated. Streams run between the meltwater. All in all, the morphology is quite complicated and one may well have doubts about the value of measurements made at a single location. The albedo sensor (at a height of $1.5 \mathrm{~m}$ above the surface) is hemispheric, but 'sees' only an area of about $10 \mathrm{~m}$ across. However, an AVHRR image (visible, channel 2), taken by the NOAA-11 satellite on 25 July 1991 for the area of Sondre Stromfjord (Fig. 2b; Knap and Oerlemans, 1996), shows a distinct band of low albedo, hundreds of kilometres long and running parallel to the ice edge. This low-albedo band extends between $20 \mathrm{~km}$ (about $800 \mathrm{~m}$ a.s.l.) and $75 \mathrm{~m}$ (about $1400 \mathrm{ma}$ a.s.l.) from the ice margin (Fig. 2b). Knap and Oerlemans (1996) report that the satellite-derived albedo values for the low-albedo band on 25 July 1991 are in a range of $0.34 \quad 0.63$, with the lowest value $(0.34)$ found about $40 \mathrm{~km}$ from the ice edge, at an elevation of about $1050 \mathrm{ma}$ a.s.l.; site 6 from the GIMEX (about $38 \mathrm{~km}$ from the ice edge) was therefore close to the minimum, and albedo values observed there $(0.27-0.53$ in July) are fairly representative for the centre of the low-albedo band. It thus appears that the strong reduction in the albedo at elevations of 800-1400 m a.s.l. on the ice sheet is a widespread feature in central West Greenland during the ablation season. This albedo pattern, which is the opposite of what is observed on mountain glaciers where the albedo normally increases with increasing altitude (e.g. Koelemeijer and others, 1993), has large implications for the energy budget and deserves careful study.

Figure 3 shows the mean profile of mass-balance observations for the years 1990-94. The mean equilibrium-line altitude (ELA) is $1431 \mathrm{~m}$ a.s.l. The transect balance of the observations $\left(N_{\text {obs }}\right)$ is $-0.99 \mathrm{~m}$ w.e. year $^{-1}$. We define the transect balance $(N)$ as:

$$
N=\frac{1}{D_{\text {tot }}} \sum_{i=1}^{n} D_{i} M_{i} .
$$

Here $M_{i}$ is the specific balance at measuring site $i, D_{i}$ is the corresponding surface distance and $D_{\text {tot }}$ is the total distance along the measured transect (about $89 \mathrm{~km}$; Fig. 1). For an easy comparison, the observed mass balance is fitted to the model grid. The transect balance of the fit $\left(N_{\text {fit }}\right)$ is $-1.19 \mathrm{~m}$ w.e. year ${ }^{-1}\left(D_{\text {tot }}=113 \mathrm{~km}\right.$; Fig. 3$)$. It should be noted that $N$ does not represent the mean specific balance of a drainage system (lack of accurate topographic data makes it impossible to define a drainage basin for this area) as usually defined. Nevertheless, it is useful to compare the models with data with respect to the mean balance along the transect.

\section{THE ENERGY-BALANGE MODEL}

Various types of models have been used to quantify the energy budget as a function of time. The assumption 
underlying a simple model is that the surface temperature is at freezing point and melting occurs whenever the surface energy budget is positive. A comprehensive model, on the other hand, calculates englacial temperature, density and water content on a vertical grid (e.g. Greuell and Konzelmann, 1994). In between these two types of model one may use a model that calculates the surface temperature by treating the ice surface as a slab with fixed heat capacity. However, although this approach has been used with some success in treating land/ocean surface in atmospheric models, it does not work well for snow and ice surfaces, because heat conduction depends so strongly on morphology. The type of model one selects depends on the purpose for which it is required and, in particular, on the amount of input data available. Regarding the annual mass balance, it has been shown by Greuell and Oerlemans (1986) that the difference in the results formed by the simple models and by the comprehensive models is rather insignificant, except where annual melt is very small. Here we will use the simple model, as we consider it to be compatible with the quality of data available for the Sondre Stromfjord transect. It is based on the model presented by Oerlemans (1991), but has been simplified so that it works with daily time steps, and, consequently, with daily mean meteorological quantities (unless stated otherwise).

The basic equations in the model are:

$$
\begin{aligned}
B & =Q+L_{\mathrm{i}}+L_{\mathrm{o}}+F_{\mathrm{s}}+F_{\mathrm{l}} \\
M & =\int_{\text {year }}\left[(1-f) \min (0 ;-B / L)+P^{*}\right] \mathrm{d} t .
\end{aligned}
$$

In Equation (2), the energy balance is denoted by $B$ and consists of absorbed short-wave radiation $(Q)$, incoming and outgoing long-wave radiation $\left(L_{\mathrm{i}}\right.$ and $\left.L_{\mathrm{o}}\right)$, and the turbulent fluxes of sensible and latent heat $\left(F_{\mathrm{s}}\right.$ and $\left.F_{\mathrm{l}}\right)$. It is assumed that melting takes place at the surface as soon as $B$ becomes positive. In Equation (3), $M$ is the specific mass balance, $f$ is the fraction of the meltwater that refreezes and does not contribute to mass loss, $L$ is the latent heat of melt and $P^{*}$ is the solid precipitation. Neither snowdrift nor water transport in the firn aquifer is taken into account. $M$ is expressed in m w.e. year ${ }^{-1}$

\section{Solar radiation}

Absorbed solar radiation $Q$ is calculated as:

$$
Q=S_{\mathrm{c}} \tau_{\mathrm{a}} \tau_{\mathrm{c}}(1-\alpha) \text {. }
$$

Here $S_{\mathrm{c}}$ is the daily amount of solar radiation on a horizontal surface at the top of the atmosphere and is derived from standard equations (Walraven, 1978). Attenuation of the solar beam by absorption and scattering and by clouds is represented by the transmissivities $\tau_{\mathrm{a}}$ and $\tau_{\mathrm{c}}$, respectively. The surface albedo is denoted by $\alpha$. For the clear-sky transmissivity we use ( $h$ is surface elevation):

$$
\tau_{\mathrm{a}}=0.75+0.000023 h .
$$

This is a fit to more detailed calculations presented in Hoogendoorn (1988), for a characteristic solar elevation of $30^{\circ}$. For the effect of clouds we follow the parameterization of Konzelmann and others (1994), which is based on data from the Greenland ice sheet:

$$
\tau_{\mathrm{c}}=1-0.78 n^{2} \exp (-0.00085 h) .
$$

Here $n$ is cloudiness (between 0 and 1 ). It should be noted that Equation (6) implies that clouds have considerably less effect on the global radiation than the parameterization used in earlier models (Oerlemans, 1991; Van de Wal and Oerlemans, 1994). The latter parameterization was based on data from the Alps, where clouds apparently are optically thicker. For typical cloud conditions in West Greenland, there can be a difference in global radiation of up to $15 \%$ (Konzelmann and others, 1994).

The albedo is treated below in a separate section.

\section{Long-wave radiation}

For the incoming long-wave radiation $L_{\mathrm{i}}$ we also follow the parameterization for daily means as presented by Konzelmann and others (1994). It reads:

$$
L_{\mathrm{i}}=\sigma T_{\mathrm{a}}^{4}\left\{\left[0.23+0.483\left(\frac{e_{\mathrm{a}}}{T_{\mathrm{a}}}\right)^{0.125}\right]\left(1-n^{3}\right)+0.96 n^{3}\right\} .
$$

Here $\sigma$ is the Stefan-Boltzmann constant, $T_{\mathrm{a}}$ is air temperature and $e_{\mathrm{a}}$ is vapour pressure $(2 \mathrm{~m}$ above the surface). For a melting surface with emissivity 1 the outgoing long-wave radiation $L_{\mathrm{o}}$ is:

$$
L_{\mathrm{o}}=315.6 \mathrm{~W} \mathrm{~m}^{-2} \text {. }
$$

\section{Turbulent fluxes}

The turbulent heat fluxes are calculated with the bulk method, in which the fluxes are set proportional to the temperature/humidity difference between atmosphere and surface, namely:

$$
\begin{aligned}
& F_{\mathrm{s}}=C\left(T_{\mathrm{a}}-T_{\mathrm{s}}\right) \\
& F_{1}=\frac{0.622 L}{c_{\mathrm{p}} p} C\left(e_{\mathrm{a}}-e_{\mathrm{as}}\right) .
\end{aligned}
$$

Here $C$ is the exchange coefficient, $L$ is the latent heat of melt, $c_{\mathrm{p}}$ is specific heat, $p$ is pressure and $e_{\text {as }}$ is saturation vapour pressure at the surface. The latter is approximated by (Kraus, 1972):

over water: $e_{\mathrm{as}}=610.8 \exp \left[19.858\left(1-273.15 / T_{\mathrm{a}}\right)\right],(11)$

over ice: $\quad e_{\mathrm{as}}=610.8 \exp \left[22.47\left(1-273.15 / T_{\mathrm{a}}\right)\right]$.

Equation (11) is used whenever the energy balance is positive.

The exchange coefficient $C$ is taken to be the same for the latent and for the sensible heat flux, but depends on altitude. This approach was used by Oerlemans (1991) and is supported by the work of Ohata (1991). On the basis of the GIMEX results, we use:

$$
C=2+22 \exp \left(\frac{-h}{500}\right) \quad(C \leq 16)
$$


A detailed discussion of Equation (13) is given in the Appendix.

\section{INPUT DATA}

Meteorological input data needed to run the model are: daily means of surface air temperature (at $2 \mathrm{~m}$ ), humidity (at $2 \mathrm{~m}$ ), cloudiness and precipitation as well as daily mean isolation.

Since only limited information is available about relative humidity, a constant value of $76 \%$ is used in the present study; the value is based on observations made at the Sondre Stromfjord weather station (DMI, 1990-92). For comparison we mention that the mean humidity measured during GIMEX-91 was $74 \%$ at site 4 (mean of 54 summer days), and $79 \%$ at site 9 (mean of July). For cloudiness we take a constant value of 0.59 (mean over the melting zone during GIMEX-91 (unpublished data)).
The $2 \mathrm{~m}$ air temperature is generated as follows:

$$
T_{\mathrm{a}}=\overline{T_{\mathrm{a}}}-\gamma h+A_{\mathrm{T}} \cos \left(\frac{2 \pi(D-12)}{365}\right) .
$$

Here $\overline{T_{\mathrm{a}}}$ is the mean annual temperature at sea level, $A_{\mathrm{T}}$ is the seasonal temperature amplitude, $D$ is the day number $(1$ January $=1)$, and $\gamma$ is the atmospheric lapse rate (taken to be $-0.0075 \mathrm{~K} \mathrm{~m}^{-1}$ on the basis of the mean of GIMEX measurements in the melting zone). Values of $\overline{T_{\mathrm{a}}}$ and $A_{\mathrm{T}}$ used in calculations (based on temperature data from the Søndre Stromfjord weather station (Ohmura, 1987) and GIMEX data) are listed in Table 1. Figure 4 shows the temperature cycle as used in the present calculations. The fit to observed data is generally good, except in late winter. This does not affect the calculations, however.

We assume that whenever air temperature is below $2{ }^{\circ} \mathrm{C}$, precipitation falls as snow. We further assume that

Table 1. Parameter values used in the models

\begin{tabular}{|c|c|c|c|}
\hline Parameter & Notation & Value & Source \\
\hline \multicolumn{4}{|l|}{ Model 1} \\
\hline Mean annual temperature & $\overline{T_{\mathrm{a}}}$ & $-3.5^{\circ} \mathrm{C}$ & This work \\
\hline Seasonal temperature amplitude & $A_{\mathrm{T}}$ & $15^{\circ} \mathrm{C}$ & This work \\
\hline Albedo of snow & $\alpha_{\mathrm{sn}}$ & 0.71 & Tuning \\
\hline Albedo of ice & $\alpha_{\text {ice }}$ & 0.40 & Tuning \\
\hline \multicolumn{4}{|l|}{ Model 2} \\
\hline Mean annual temperature & $\overline{T_{\mathrm{a}}}$ & $-3.5^{\circ} \mathrm{C}$ & This work \\
\hline Seasonal temperature amplitude & $A_{\mathrm{T}}$ & $15^{\circ} \mathrm{C}$ & This work \\
\hline Albedo of snow & $\alpha_{\mathrm{sn}}$ & 0.75 & GIMEX-91, see text \\
\hline Background albedo & $\alpha_{\mathrm{b}}$ & varies & Oerlemans, 1991 \\
\hline \multirow[t]{4}{*}{ Constants } & $a_{1}$ & 0.12 & Tuning \\
\hline & $a_{2}$ & $500 \mathrm{~m}$ & Tuning \\
\hline & $a_{3}$ & $250 \mathrm{~m}$ & Tuning \\
\hline & $a_{4}$ & 0.54 & Tuning \\
\hline \multicolumn{4}{|l|}{ Model 3} \\
\hline Mean annual temperature & $\overline{T_{\mathrm{a}}}$ & $-3.5^{\circ} \mathrm{C}$ & This work \\
\hline Seasonal temperature amplitude & $A_{\mathrm{T}}$ & $15^{\circ} \mathrm{C}$ & This work \\
\hline Albedo of snow & $\alpha_{\mathrm{sn}}$ & 0.75 & GIMEX-91, see text \\
\hline Background albedo & $\alpha_{\mathrm{b}}$ & varies & Oerlemans, 1991 \\
\hline \multirow[t]{4}{*}{ Constants } & $a_{1}$ & 0.11 & Tuning \\
\hline & $a_{2}$ & $500 \mathrm{~m}$ & Tuning \\
\hline & $a_{3}$ & $350 \mathrm{~m}$ & Tuning \\
\hline & $a_{4}$ & 0.49 & Tuning \\
\hline \multicolumn{4}{|l|}{ Model 4} \\
\hline Mean annual temperature & $\overline{T_{\mathrm{a}}}$ & $-3.0^{\circ} \mathrm{C}$ & This work \\
\hline Seasonal temperature amplitude & $A_{\mathrm{T}}$ & $15^{\circ} \mathrm{C}$ & This work \\
\hline Albedo of snow & $\alpha_{\mathrm{sn}}$ & 0.75 & GIMEX-91, see text \\
\hline Albedo of ice & $\alpha_{\text {ice }}$ & 0.55 & GIMEX-91, see text \\
\hline Albedo of water & $\alpha_{\text {wat }}$ & 0.15 & Hummel and Reck, 1979 \\
\hline Albedo of slush & $\alpha_{\mathrm{sl}}$ & 0.45 & This work \\
\hline Scaling factor for meltwater & $w^{*}$ & $0.20 \mathrm{~m}$ & Tuning \\
\hline \multirow[t]{3}{*}{ Constants } & $c_{1}$ & $1.5 \mathrm{~d}$ & Tuning \\
\hline & $c_{2}$ & $25 \mathrm{~d}$ & Tuning \\
\hline & $c_{3}$ & 140 & Tuning \\
\hline
\end{tabular}




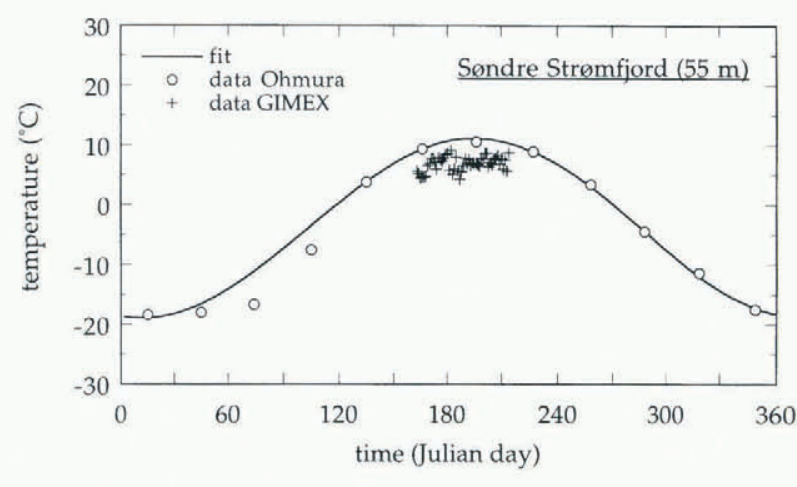

Fig. 4. The temperature cycle used in the model calculations, based on Ohmura and Reeh (1991) and the GIMEX measurements.

precipitation occurs on one day out of 15 ; therefore there are about two significant precipitation events per month. We did not attempt to use different precipitation rates for different months, since information from the Sondre Stromfjord weather station cannot be considered representative for the ice sheet (it is known that Sondre Stromfjord has more precipitation in summer because of convective showers; however, these hardly occur further up the ice sheet). On the basis of the annual precipitation at Sondre Stromfjord $\left(0.16\right.$ m year $\left.^{-1}\right)$ and the precipitation map of Ohmura and Reeh (1991), we use the following linear expression with altitude as variable:

$$
P=0.16+0.0000578 h \text {. }
$$

Thus, between the ice margin and the higher part of the model transect the precipitation rate $P$ increases by $80 \%$.

\section{SURFAGE PROGESSES AND ALBEDO}

The parameterization of the albedo is closely connected with the way in which the surface is treated. We consider a hierarchy of model versions, in order to find out how the simulation of observed albedo and specific balance can be significantly improved. The model versions are:

1. Two-albedo model. $\alpha=0.71$ (snow) or 0.40 (ice).

2. No-refreezing model. $\alpha$ as in Oerlemans (1991).

3. Simple-refreezing model. $\alpha$ as in Oerlemans (1991).

4. Meltwater model. $\alpha$ depends on snow density and the presence of slush and meltwater.

Below we give a description of each of the model versions. Since new parameterizations on surface mass balance and surface albedo are used in the meltwater model, we will discuss these in detail.

\section{Model 1: the two-albedo model}

The albedo can have only two values, one for snow and one for ice. This implies that the albedo above the equilibrium line is constant in space and time. Below the equilibrium line it jumps from the snow value to the ice value as soon as all snow has melted. In this model version, there is no refreezing, i.e. in Equation (3) $f=0$ all the time. Whenever the energy budget becomes positive $(B>0)$, snow or ice has begun to melt. The meltwater runs off immediately.

\section{Model 2: the no-refreezing model}

In the mass-balance model presented in Oerlemans (1991), the albedo was calculated from:

$$
\begin{gathered}
\alpha=\max \left[0.12 ; \alpha_{\mathrm{sn}}-\left(\alpha_{\mathrm{sn}}-\alpha_{\mathrm{b}}\right) \exp \left(-5 d_{\mathrm{sn}}\right)\right. \\
\left.-0.015 M_{\mathrm{m}}\right] .
\end{gathered}
$$

Here $\alpha_{\mathrm{sn}}$ is the albedo of snow, $d_{\mathrm{sn}}$ is the snow depth, $M_{\mathrm{m}}$ is the accumulated melt during the ablation season, and $\alpha_{\mathrm{b}}$ is the background albedo. $\alpha_{\mathrm{b}}$ is defined as:

$$
\alpha_{\mathrm{b}}=a_{1} \arctan \left(\frac{h-E+a_{2}}{a_{3}}\right)+a_{4} .
$$

Here $E$ is the ELA and $a_{1}, a_{2}, a_{3}$ and $a_{4}$ are constants. To obtain a smooth transition between $\alpha_{\mathrm{b}}$ and $\alpha_{\mathrm{sn}}$, the increase in the albedo is assumed to be a smooth function of snow depth $d_{\mathrm{sn}}$. Here again, refreezing is neglected.

\section{Model 3: the simple-refreezing model}

In this model version the albedo is calculated in essentially the same way as in model 2, except that different values are used for the constants in Equation (17) due to the inclusion of the refreezing effect in the model. We will discuss this later.

The effect of the refreezing of meltwater is included in the model in a simple manner, as described in Oerlemans (1992). Meltwater that penetrates into snowpack will refreeze and remain there if the temperature is below melting point. It is assumed that during the melting period an upper layer with a heat capacity equivalent to $2 \mathrm{~m}$ of solid ice (density $\rho_{\text {ice }}=900 \mathrm{~kg} \mathrm{~m}^{-3}$ ) will be heated; in this layer the ice temperature will be brought up to melting point. The fraction of energy involved in melting ice or snow $\left(B_{\text {ice }}\right)$ increases as the ice temperature $\left(T_{\text {ice }}\right)$ rises in the ablation season. Consequently, the heat flux into the upper ice/snow layer $\left(H_{\text {ice }}\right)$ decreases and becomes zero as soon as the ice temperature reaches zero. The equations used read (Oerlemans, 1992):

$B_{\text {ice }}=B \exp \left(T_{\text {ice }}\right)$

$H_{\text {ice }}=B-B_{\text {ice }}=B\left[1-\exp \left(T_{\text {ice }}\right)\right]$

$\left(T_{\text {ice }} \leq 0\right)$

$T_{\text {ice }}$ is set equal to the annual mean temperature at the beginning of each balance year. Change of $T_{\text {ice }}$ can then take place only through refreezing of meltwater when the ablation season starts. This means that the higher the elevation, the lower the temperature, and thus the harder it is for significant runoff to begin.

\section{Model 4: the meltwater model}

In this model version the albedo depends on snow density and on the presence of slush and meltwater at the surface. 
It is known that in some way the large variations in the albedo are primarily related to the presence of meltwater at the surface. We have come to the conclusion that a realistic parameterization for the albedo can only be achieved if the amount of meltwater is tracked. This is difficult, however. Models exist for the transport of water through firn (e.g. Ambach and others, 1981), but these are not applicable, since in the zone we are studying there is no uniform firn layer. The flow in the meltwater channels can be described by simple hydraulics, but this does not seem to be the important issue. What really determines the time-scale of the surficial meltwater runoff (averaged over a $2 \mathrm{~km} \times 2 \mathrm{~km}$ area, for instance) is the time the water takes to reach the drainage system. In fact, from the time melting begins until the moment meltwater runs off, the surface of the ice sheet undergoes a complicated metamorphosis which changes the state of the surface dramatically and thus determines the behaviour of meltwater on the surface. This consequently affects the surface albedo. In the light of this, the surface albedo is modelled in such a way that it can simulate the following regimes: (i) decrease in the albedo during the first part of the melting season $\left(d_{\mathrm{sn}}>0\right)$ due to the densification of the snowpack; (ii) decrease in the albedo associated with accumulation of meltwater during the rest of the melting period when the surface is snow-free $\left(d_{\mathrm{sn}}=0\right)$. Figure 5 depicts a schematic structure of the parameterizations used in the model for surface mass balance and surface albedo.

\section{Surface mass balance}

The available positive energy $(B)$, as calculated by Equation (2), is used to melt snow and ice in the following steps:
Snow melts. All meltwater is allowed to penetrate downwards into the snow cover and refreeze there as superimposed ice $\left(d_{\mathrm{si}}\right)$. The snow cover $\left(d_{\mathrm{sn}}\right)$ is defined as a snow layer that has accumulated since the end of the previous melting season (starting from Julian day 230,18 August). It is added with snowfall $\left(P^{*}\right)$ and subtracted with melting $\left(h_{\mathrm{mt}}\right)$.

The corresponding energy of the refreezing is used to heat up the snow layer. The mean temperature of the snow layer $\left(T_{\mathrm{sn}}\right)$ is brought up towards the melting point. The snowpack is densified due to melting and refreezing. At this stage, no runoff takes place and there is no change in mass.

The snow temperature $\left(T_{\mathrm{sn}}\right)$ exceeds the melting point; $T_{\mathrm{sn}}$ is put equal to $0^{\circ} \mathrm{C}$. The meltwater percolates into the snow to build up a slush layer $\left(d_{\mathrm{sl}}\right)$ (a snow layer saturated with water). The slush $\left(d_{\mathrm{si}}\right)$ does not exceed the snow cover $\left(d_{\mathrm{sn}}\right)$. The densification of the snowpack continues. Runoff $(R)$ starts.

The snow/slush has melted away. The superimposed ice melts. Depending on the surface slope $(S)$, meltwater $(W)$ starts accumulating on the surface.

The ice melts.

\section{Surface albedo parameterization}

The surface albedo is calculated according to the state of the surface (snow/slush/ice):

During the melting season $(B>0)$, until the cold storage of the winter snow has been eliminated $\left(d_{\mathrm{sn}}=0\right)$, the albedo is assumed to be a linear
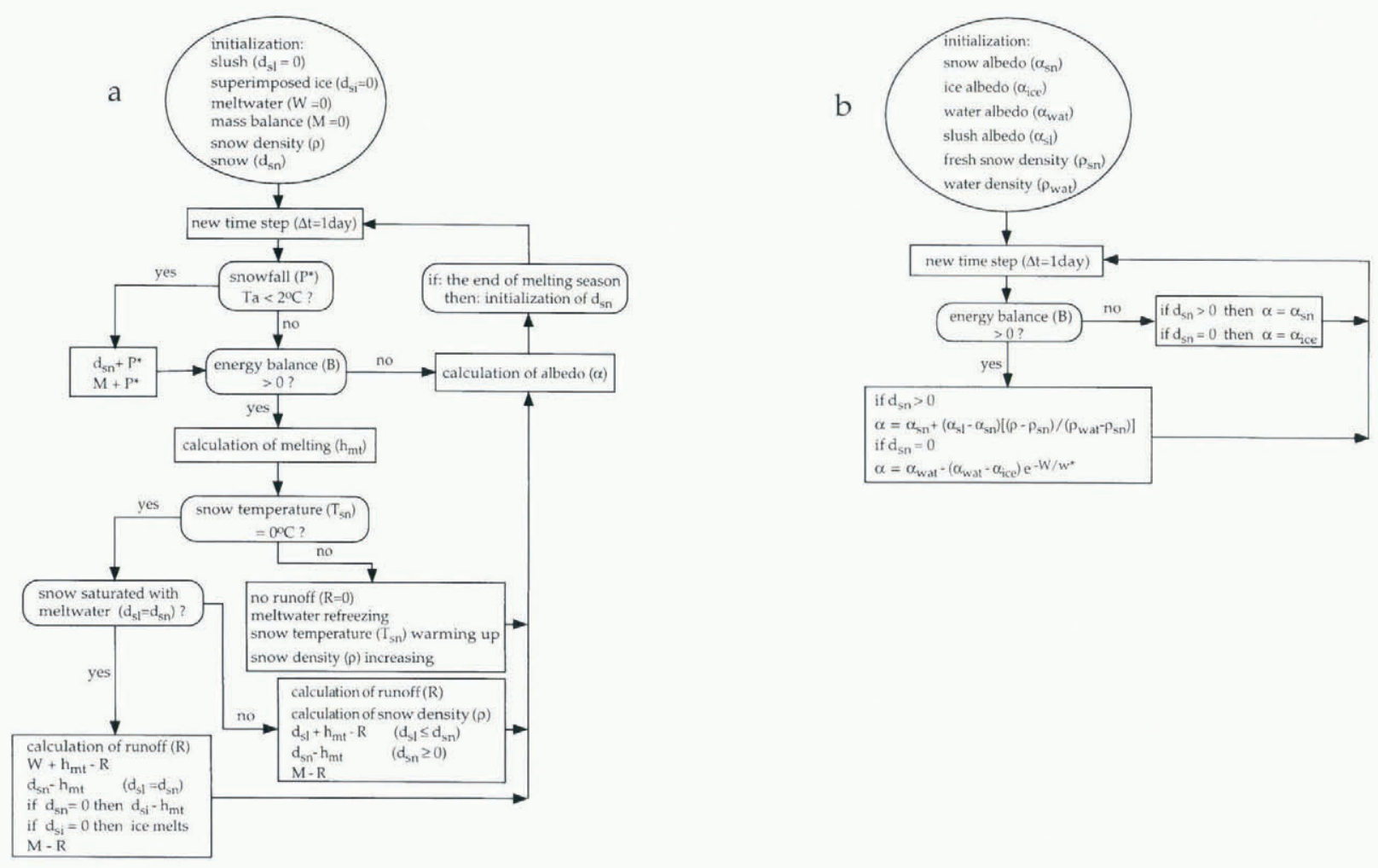

Fig. 5. Schematic structure of parameterization adopted in the meltwater model for (a) surface mass balance and (b) surface albedo. 
fraction of the mean density of the snowpack $(\rho)$; from the moment the surface becomes snow-free, the albedo is determined by the amount of meltwater at the surface $(W)$. In formulating the latter regime, we ensure a smooth transition between ice and water albedo by using an exponential function.

Outside the melting season $(B \leq 0)$, albedo is set either to the snow albedo $\left(\alpha_{\mathrm{sn}}\right)$ or to the ice albedo $\left(\alpha_{\text {ice }}\right)$, depending on the properties of the surface.

Thus, the surface albedo is lower for higher density and larger wetness of the surface. The parameterization is based on the notion that density and wetness may represent the effects of surface roughness, grain-size and liquid-water content (Warren, 1982; Greuell and Konzelmann, 1994).

Densification by metamorphosis includes the effect of snowfall, refreezing and melting:

$$
\rho=\frac{\left(d_{\mathrm{sn}}+d_{\mathrm{si}}+d_{\mathrm{sl}}\right) \rho_{\mathrm{sn}}}{d_{\mathrm{sn}}} \quad\left(d_{\mathrm{si}} \leq d_{\mathrm{sn}}, d_{\mathrm{sl}} \leq d_{\mathrm{sn}}, d_{\mathrm{sn}}>0\right)
$$

Here $\rho$ is the mean density of the snow cover in $\mathrm{kg} \mathrm{m}^{-3}$ and $\rho_{\mathrm{sn}}$ is the density of fresh snow (assumed to be 300 $\left.\mathrm{kg} \mathrm{m}^{-3}\right)$. It is obvious that the mean density $\rho$ increases with increasing melting.

Because the ice temperature at the depth of a few metres is below melting point, the meltwater channels remain at the surface until they approach the ice margin and disappear in moulins (this happens typically a few kilometres from the ice edge). Meltwater probably reaches the drainage system quicker when the general surface slope is larger. Therefore, we decided to use an equation for the area-averaged surficial meltwater $W$ which takes into account surface slope $S$ in such a way that it can find:

a finite value for $s=0$

a finite value for $S \rightarrow \infty$.

The equation reads:

$$
\frac{\mathrm{d} W}{\mathrm{~d} t}=P_{\mathrm{w}}-\frac{W}{t^{*}}
$$

where

$$
\begin{array}{lll}
t^{*}=c_{1}+c_{2} \exp \left(-c_{3} S\right) & S \rightarrow \infty \quad t^{*} \rightarrow c_{1} \\
& S \rightarrow 0 \quad t^{*} \rightarrow c_{1}+c_{2} .
\end{array}
$$

Here $P_{\mathrm{w}}$ is the production of meltwater that does not refreeze and $t^{*}$ is the characteristic time-scale for meltwater runoff as mentioned above. The surface slope $S$ is derived from a fit to the altitude profile along the GIMEX transect which was inferred from differential GPS measurements (Fig. 1). Equation (22) contains three constants that have to be chosen. Unfortunately, no information is available concerning the amount of surficial water over the course of time. So the best one can do is to determine optimal values for $c_{1}, c_{2}$ and $c_{3}$ by optimizing the simulated albedo against the observations and at the same time taking into account that the obtained $t^{*}$ is realistic. In light of this the values of $c_{1}, c_{2}$ and $c_{3}$ used in the model are 1.5, 25 and 140, respectively (Table 1). Thus, all meltwater at the surface would drain away within $1-2 \mathrm{~d}$ if the surface slope is very large, while it would take about $26 \mathrm{~d}$ to drain away all meltwater on a flat surface with the slope close to $0^{\circ}$.

The expressions for the albedo in all situations therefore read:

$$
\begin{aligned}
& \text { if } B>0 \\
& \alpha=\alpha_{\mathrm{sn}}+\left(\alpha_{\mathrm{sl}}-\alpha_{\mathrm{sn}}\left[\frac{\rho-\rho_{\mathrm{sn}}}{\rho_{\mathrm{wat}}-\rho_{\mathrm{sn}}}\right] \quad\left(d_{\mathrm{sn}}>0\right)\right. \\
& \alpha=\alpha_{\text {wat }}-\left(\alpha_{\text {wat }}-\alpha_{\text {ice }}\right) \exp \left(\frac{-W}{w^{*}}\right) \quad\left(d_{\text {sn }}=0\right) \\
& \text { if } B \leq 0 \\
& \alpha=\alpha_{\mathrm{sn}} \\
& \left(d_{\mathrm{sn}}>0\right) \\
& \alpha=\alpha_{\text {ice }} \\
& \left(d_{\mathrm{sn}}=0\right)
\end{aligned}
$$

Here $\alpha_{\text {wat }}$ is the albedo of water, $\alpha_{\mathrm{sl}}$ is the albedo of slush, $\rho_{\text {wat }}$ is the density of water $\left(1000 \mathrm{~kg} \mathrm{~m}^{-3}\right)$ and $w^{*}$ is a constant. The values of $\alpha_{\mathrm{sn}}, \alpha_{\mathrm{sl}}, \alpha_{\text {wat }}$ and $\alpha_{\text {ice }}$ are taken to be constants (see Table 1). In the present version of the model, 0.75 is taken as the mean snow albedo, an intermediate value of the observations at site 9 (ranging from 0.64 to 0.89 ; GIMEX-91). The slush albedo 0.45 ; Table 1) is chosen rather arbitrarily because no information is available. Since slush is in fact a mixture of snow and water, we feel that an intermediate value between the snow albedo $(0.75)$ and the water albedo $(0.15)$ may be a reasonable approximation, because what we deal with is not a uniform saturated snow layer but a patchy surface where some parts are wet and melting, and other parts are covered by snow. What we want to express here by a gradual transition from snow albedo to slush albedo does not represent an albedo change at a single spot where albedo "jumps" from snow to slush due to the water table in the snow rising to the snow surface, as observed in the field, but a mean effect of the albedo transition at surface where some parts are covered by slush or water and other parts are covered by snow during the early period of melting. As initial condition we take a bare-ice surface, with an ice albedo of 0.55 (based on the observations of GIMEX-91). Note that the albedo prescribed a priori is not altitude-dependent.

\section{SIMULATION OF A REFERENCE STATE}

Comparison of models is meaningful only when they are calibrated against the same data. We have adjusted model parameters (Table 1) in such a way that all models correctly simulate:

the observed mean ELA, E (1431 m; Fig. 3);

the observed transect balance, $N_{\text {fit }}(-1.19$ mw.e. year $^{-1}$; Fig. 3).

The integration of the energy-balance model was performed with a ld time step, starting on 1 January. Calculations were done for a number of grid points which have equal distance in elevation at intervals of $150 \mathrm{~m}$. Results of the reference experiment are presented in Figures 6-9. 
Figure 6 shows comparisons between the observed (mean of 1990 94) and the calculated mass balance for all four models. The modelled mass balance generally agrees well with the measurements except for the lower reaches of the transect (Fig. 6a and b). It seems that among the four model versions the meltwater model (model 4) performs best in reproducing the balance variations along the transect. Surprisingly, the simplest model version (model 1) does a good job as well. The specific balance at the lower part of the transect (below $500 \mathrm{~m}$ a.s.l.) is not well predicted by the other models (models 2 and 3; Fig. 6). Calculations using model 4 indicate that the absorbed short-wave radiation $\left(136 \mathrm{~W} \mathrm{~m}^{-2}\right.$, daily mean for the GIMEX-91 period 10 June-31 July), at $350 \mathrm{ma.s.l.}$ accounts for $70 \%$ of the total energy available for melting. This agrees with the measured absorbed shortwave radiation $117 \mathrm{~W} \mathrm{~m}^{2}$, daily mean for the same period) at site $4(340 \mathrm{~m}$ a.s.l., Fig. 1) which accounts for $73 \%$ of the total. Significant overestimates of ablation arrived at using models 2 and 3 (Fig. 6b) can be explained by the effect of the unrealistically low surface albedo that the model generates for the ice margin.
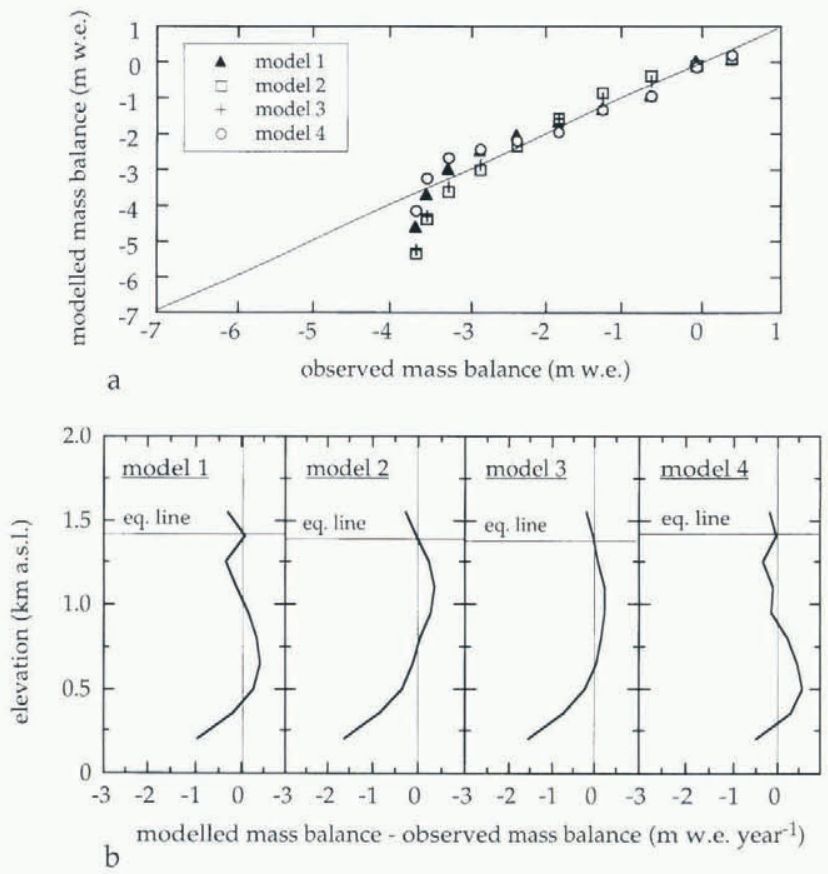

Fig. 6. Comparisons between the (a) observed (mean of 1990 -94) and the (b) calculated mass balance in the reference experiment for all four models: (a) the modelled mass balance plotted against the observations; (b) elevation dependence of the differences between the modelled and the observed mass balance.

The transect balance $(N$; Equation (1)) computed by means of all the models is compatible with the observations $\left(N_{\text {fit }}\right.$; Fig. 3). The difference between $N$ and $N_{\text {fit }}$ in all cases is less than $3 \%$. Obviously it is possible to fit the measured transect balance quite well by tuning the model parameters regardless of the model schemes. However, how well can the models reproduce the temporal variations of the melting observed in the field? Are the models capable of predicting the albedo variations seen along the transect? Figure 7 illustrates the computed and the measured time dependence of the melting at site 4 during the summer period for all the models. Of the four models, model 4 (the meltwater model) apparently does the best job. It should be realized that fitting the transect balance well alone is not very meaningful if the observed temporal and spatial variations of the ablation cannot be correctly simulated.

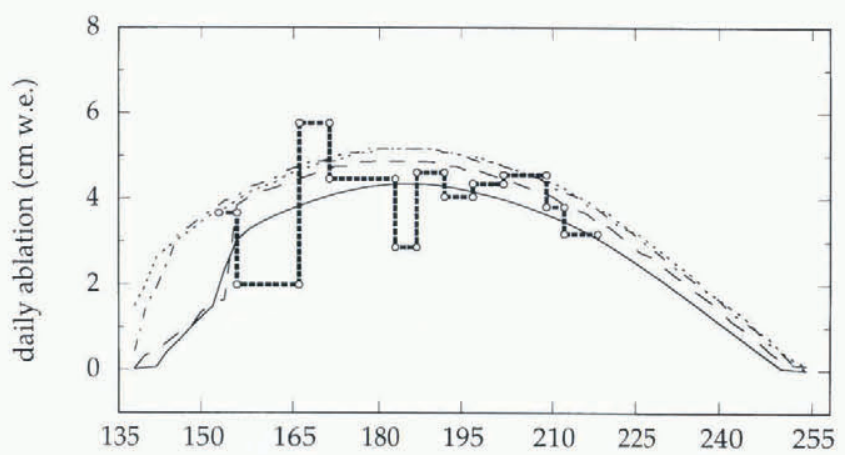

a

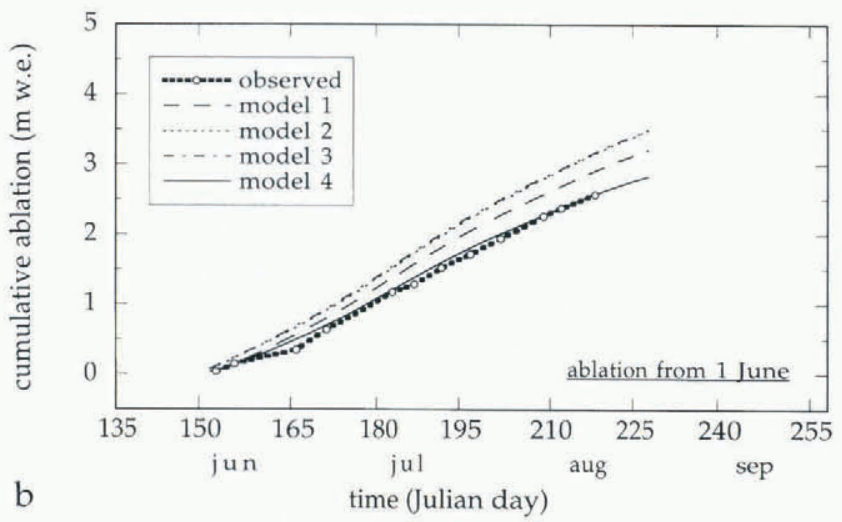

Fig. 7. Comparisons between the measured and the modelled time dependence of the melting at site 4 (337 ma.s.l.; GIMEX-91) during the summer period for all the models: (a) daily ablation; (b) cumulative ablation.

Figure 8 presents a comparison between the observed (GIMEX-91) and the calculated surface albedo for model 4. It appears that a better simulation of observed albedo can indeed be obtained if water at the surface is explicitly included in the model. There is still a significant discrepancy between the calculated and the observed albedo, however, especially at sites 5 and 6 . It should be mentioned that, when GIMEX-91 was being set up in early June 1991, there was still some snow cover around site 6 . However, the mast was eventually put up on bare ice instead of snow, because the task was simpler. This partly explains the discrepancy between the observed and the calculated albedo for site 6 during the onset of the ablation season. The difference between the calculated and the observed albedo at site 9 can be explained by the fact that a mean value 0.75 , on the basis of the albedo observations at site 9 ) was taken as the snow albedo in the model, and that the effect of snow ageing was not included in the calculation. The calculated albedo at site 9 thus cannot depict the particular variations due to those precipitation events and the snow-ageing effect. Never- 


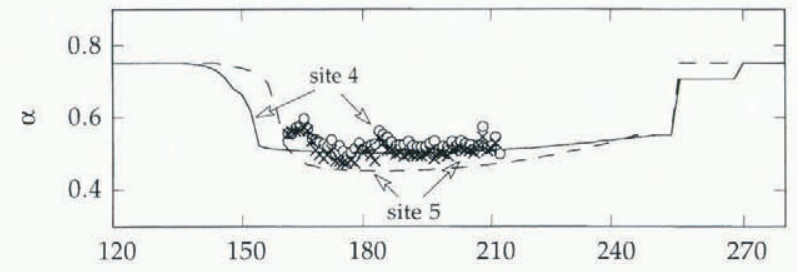

a

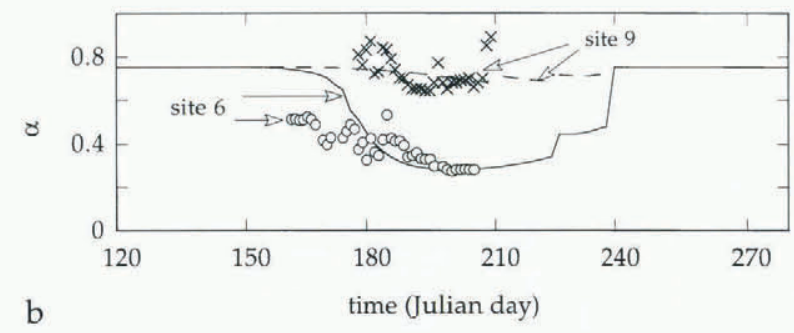

Fig. 8. Temporal variation of surface albedo at (a) sites 4 and 5, $(b)$ sites 6 and 9 along the Sondre Stromfjord transect. Lines are the model results; symbols are the observed data collected during GIMEX-91.

theless, the model is able to reproduce the major characteristics of the albedo pattern in the melting zone along the Sondre Stromfjord transect. On the other hand, the simulated albedo variation derived from models 1,2 and 3 could in no way compare with the observations. The reason is clear. In model 1, only two values are assigned to the albedo, no allowance being made for spatial and temporal variation. There is simply a switch from one value to the other. In models 2 and 3 , the effect of meltwater is not considered in the scheme.

To find out how realistically model 4 performs, the simulated temporal variation in various quantities during the melting season for the Søndre Strømfjord transect is plotted in Figure 9. As seen in the figure, the melting period $(B>0)$, at the grid point at $200 \mathrm{~m}$ a.s.l., starts in late May and lasts for about 3.5 months, whereas higher up on the ice sheet, near the equilibrium line, melting does not occur until the end of June and lasts for approximately 1 month (Fig. 9f). As soon as the ablation begins, the snow layer is heated up to melting point in a matter of days (2-6d; Fig. 9c), and the mean density of the snowpack increases rapidly (Fig. 9b). As melting progresses, runoff begins; water starts to accumulate on the surface; a slush layer builds up and snow gradually melts away. At the ice margin, the whole process of snowpack elimination (for example, snow depth of $0.12 \mathrm{~m}$ w.e.) takes about $10 \mathrm{~d}$, whereas high up on the ice, $25 \mathrm{~d}$ are needed to melt away a snowpack of $0.16 \mathrm{~m}$ w.e. (Fig. 9d). This is reasonable and is supported by field observations (Henneken and others, 1994). Therefore, it can be concluded that the surface conditions and transect balance along the Sondre Stromfjord transect have been simulated satisfactorily, and a set of sensitivity tests can now be attempted.

\section{GLIMATE SENSITIVITY}

In this section we investigate the implications of the various models for the sensitivity of specific balance to

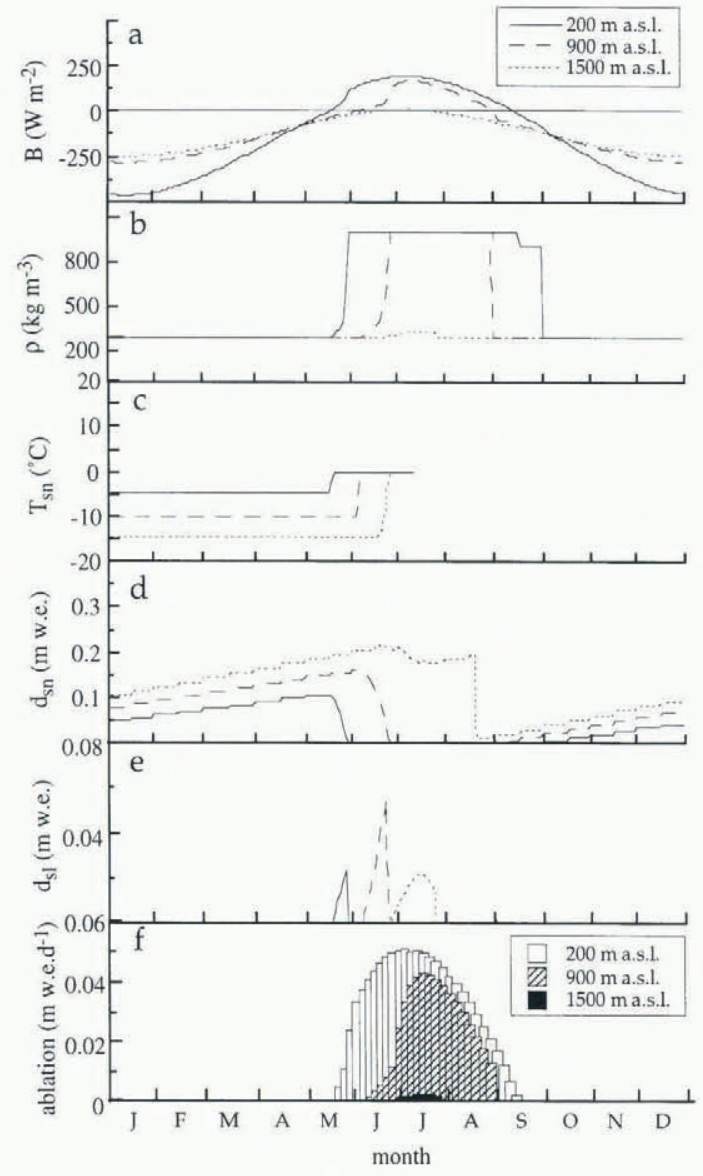

Fig. 9. (a) Energy budget $B$, (b) mean snow density $\rho$, (c) mean snow temperature $T_{\mathrm{sn}}$, (d) snow depth $d_{\mathrm{sn}}$, (e) slush depth $d_{\mathrm{sl}}$ and $(f)$ ablation as a function of time for three different grid points along the Sondre Stromfjord transect.

changes in air temperature and precipitation.

First, we made calculations for perturbations of $+1 \mathrm{~K}$ in air temperature. It has been suggested, however, that increasing temperature on the Greenland ice sheet also involves somewhat higher precipitation rates (e.g. Huybrechts and others, 1991). Therefore we also carried out model runs with combined perturbations in air temperature and precipitation (a $+1 \mathrm{~K}$ temperature change with a $+5 \%$ change in precipitation). Changes in transect balance $(\Delta N)$ and in ELA $(\Delta E)$ for all the models are summarised in Figure 10.

It is clear that values of $\Delta N$ are not very different (the increased ablation ranging from $40 \%$ to $45 \%$ for a $1 \mathrm{~K}$ warming); in the case of combined perturbations, the differences in $\Delta N$ are slightly larger (the increased ablation ranging from $31 \%$ to $39 \%$; Fig. 10a). For changes in ELA, model 1 appears to be the most sensitive (Fig. 10b). This is probably due to the discontinuity in the albedo transition between snow and ice.

With regard to changes in mass-balance profiles, however, the picture looks different (Fig. 11). There are large differences between the models. The change in mass balance in model 1 shows a sharp peak around $1400 \mathrm{~m}$ a.s.l. elevation. This is obviously caused by the jump in albedo as discussed previously. The largest change at mid-elevation seen in model 2 can be explained by the albedo feedback. A lifting of the ELA due to a $1 \mathrm{~K}$ 

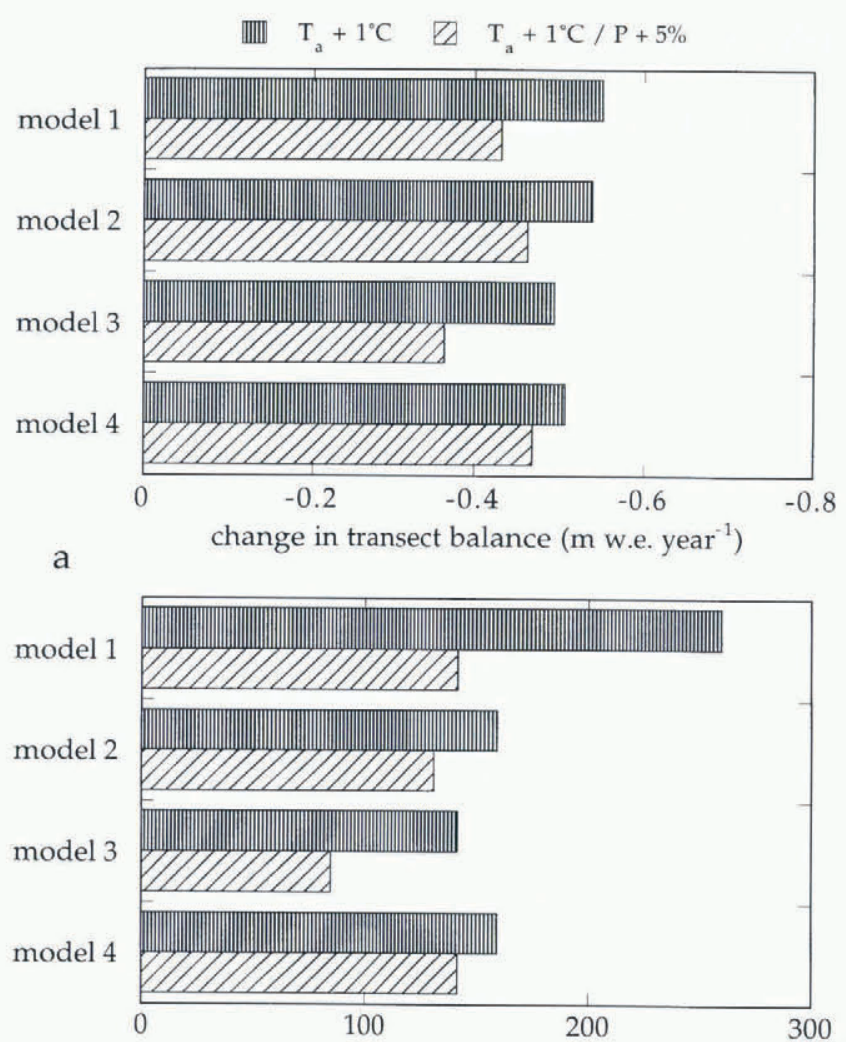

b

change in equilibrium-line altitude ( $m$ a.s.l.)

Fig. 10. Changes in (a) transect balance and ( $b$ ) equilibrium-line altitude for perturbations in air temperature and precipilation for all the models.

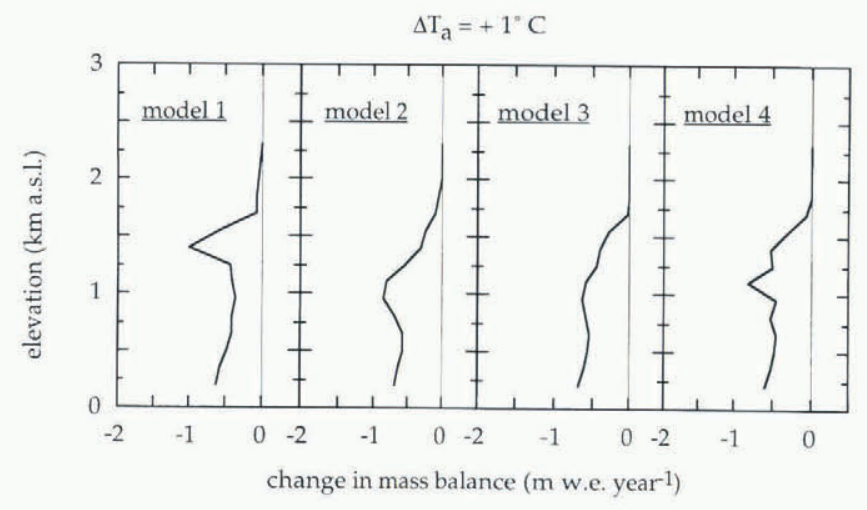

Fig. 11. Sensitivity of the mass-balance profile to changes in air temperature for all the model versions.

warming reduces the albedo significantly, thus reducing the surface albedo and enhancing the melting. Model 3 behaves similarly but with a less pronounced midelevation maximum because of the effect of refreezing. With the meltwater-albedo coupling in model 4 , the changes in specific balance reach a maximum just below the equilibrium line. On the lower part of the ice sheet, however, the change in mass balance tends to become independent of elevation. On the basis of estimates made with the meltwater model, a $1 \mathrm{~K}$ increase in the annual mean air temperature leads to a change of $161 \mathrm{~m}$ in the ELA, and the transect balance changes from -1.22 to $-1.72 \mathrm{~m}$ w.e. year ${ }^{-1}$ (the mean ablation increases by $0.5 \mathrm{~m}$ w.e. year $\left.^{-1}\right)$.
It should also be noted that a change in precipitation has only a slight effect. A very large change in precipitation would be needed to cancel out the temperature effect.

\section{CONGLUSIONS}

Four energy-balance models have been presented. Although all are capable of predicting the transect balance reasonably well, only the meltwater model is able to reproduce the albedo pattern and the massbalance profile which were observed along the Sondre Stromfjord transect in central West Greenland. When meltwater and its effect on albedo are included in the model, the simulation of albedo and mass balance improves considerably.

Sensitivity tests show that the largest response of the specific balance to temperature and precipitation changes occurs just below the equilibrium line. This is in contrast to findings for mountain glaciers (where sensitivity decreases with increasing altitude; Greuell and Oerlemans, 1986; Oerlemans and Hoogendoorn, 1989). In case of climate warming, low-albedo zones may become widespread and lead to significant additional runoff from the ice sheet.

We have modelled the densification of the upper snowpack and the amount of meltwater contributing to a lowering of the surface albedo with a simple approach. It should be possible to refine the model considerably, but this will be worthwhile only if more extensive data become available. Such data must be derived from carefully calibrated and validated remote-sensing products and must have sufficient spatial and temporal resolution.

It is not clear how widespread the occurrence of "lowalbedo zones" over the Greenland ice sheet is. Also, at this stage it is not possible to identify areas having the characteristics that will turn them into low-albedo zones if there is significant climate warming. However, the large increase in ablation rates when the meltwater-albedo feedback is included implies a potentially important mechanism that may affect the balance of the whole ice sheet. Further study of this topic is needed.

\section{ACKNOWLEDGEMENTS}

We are very grateful to R. Bintanja, M. van den Broeke and W. Greuell for discussing so many parts of this work. Financial support was obtained from the Commission of the European Communities, under contract Nos. EV5VCT91-0051 and EV5V-CT92-0132 (Environment), and fron the Dutch National Research Programme on Global Air Pollution and Climate Change (contract 276/91NOP).

\section{REFERENCES}

Ambach, W. 1979. Zur Nettoeisablation in einem Höhenprofil am grönländischen Inlandeis. Polarforschung, 49 (1), 55-62.

Ambach, W., M. Blumthaler and P. Kirchlechner. 1981. Application of the gravity flow theory to the percolation of melt water through firn. f. Glaciol., $27(95), 67-75$. 
Braithwaite, R.J. and O. B. Olesen. 1989. Calculation of glacier ablation from air temperature, West Greenland. In Oerlemans, J., ed. Glacier fluctuations and climatic change. Dordrecht, etc., Kluwer Academic Publishers, 219-233.

Braithwaite, R.J. and O.B. Olesen. 1990. Increased ablation at the margin of the Greenland ice sheet under a greenhouse-effect climate. Ann. Glaciol., 14, 2022.

Greuell, W. and T. Konzelmann. 1994. Numerical modeling of the energy balance and the englacial temperature of the Greenland ice sheet: calculations for the ETH-Camp location (West Greenland, $1155 \mathrm{~m}$ a.s.l.). Global and Planetary Change, 9 1-2), 91-114.

Greuell, W. and J. Oerlemans. 1986. Sensitivity studies with a mass balance model including temperature profile calculations inside the glacier. Z. Gletscherkd. Glazialgeol., 22 2), 101-124.

Henneken, E. A. C., N.J. Bink, H. F. Vugts, F. Cannemeijer and A. G. C. A. Meesters. 1994. A case study of the daily energy balance near the equilibrium line on the Greenland ice sheet. Global and Planetary Change, 9 1-2), 69-78.

Hoogendoorn, N.C. 1988. De massbalans van alpengletsjers. Utrecht, University of Utrecht. Institut voor Meteorologic en Fysische Oceanografie. (Verslag 88-14.)

Hummel, J. R. and R. A. Reck. 1979. A global surface albedo model. J. Appl. Meteorol., 18, 239-253.

Huybrechts, P., A. Letréguilly and N. Reeh. 1991. The Greenland ice sheet and greenhouse warming. Global and Planetary Change, 3 4), 399-412.

Knap, W.H. and J. Oerlemans. 1996. The surface albedo of the Greenland ice sheet: satellite-derived and in situ measurements in the Sondre Stromfjord area during the 1991 melt season. J. Glaciol., $42(141), 364374$.

Koelemeijer, R., J. Oerlemans and S. Tjemkes. 1993. Surface reflectance of Hintereisferner, Austria, from Landsat 5 TM imagery. Ann. Glaciol., 17, 17-22.

Konzelmann, T., R.S.W. van de Wal, J.W. Greuell, R. Bintanja, E. A. C. Henneken and A. Abe-Ouchi. 1994. Parameterization of global and longwave incoming radiation for the Greenland ice sheet. Global and Planetary Change, $9(1-2), 143-164$.

Kraus, E. B. 1972. Atmosphere-ocean interaction. Oxford, Clarendon Press.

Munro, D.S. 1989. Surface roughness and bulk heat transfer on a glacier: comparison with eddy correlation. f. Glaciol., 35 (121), 343-348.

Oerlemans, J. 1991. The mass balance of the Greenland ice sheet: sensitivity to climate change as revealed by energy-balance modelling. Holocene, 1 (1), 4049.

Ocrlemans, J. 1992. Climate sensitivity of glaciers in southern Norway: application of an energy-balance model to Nigardsbreen, Hellstugubreen and Alfotbreen. J. Glaciol., 38(129), 223-232.

Oerlemans, J. and N.C. Hoogendoorn. 1989. Mass-balance gradients and climatic change. 7. Glaciol., 35 (121), 399405.

Oerlemans, J. and H.F. Vugts. 1993. A meteorological experiment in the melting zone of the Greenland ice sheet. Bull. Am. Meteorol. Soc. 74 3$), 355-365$

Ohata, T. 1991. The effect of glacier wind on local climate, turbulent heat fluxes and ablation. Z. Gletscherkd. Glazialgeol., 25 (1), 1989, 4968.

Ohmura, A. 1987. New temperature distribution maps for Greenland. z. Gletscherkd. Glazialgeol., 23 1), 1-45.

Ohmura, A. and N. Reeh. 1991. New precipitation and accumulation maps for Greenland. J. Glaciol., 37 (125), 140-148.

Ohmura, A. and M. Wild. 1995. A possible change in mass balance of Greenland and Antarctic ice sheets in the coming century. Gronlands Geologiske Undersogelse, Ser. Open File, 95/5, 59-77.

Ohmura, A. and 10 others. 1992. Energy and mass balance during the melt season at the equilibrium line altitude, Paakitsoq, Greenland ice sheet (69 $34^{\prime} 25.3^{\prime \prime}$ North, $49^{\circ} 17^{\prime} 44 . l^{\prime \prime}$ West, 1155 m a.s.l.). Zürich, Eidgenössische Technische Hochschule. Department of Geography. (ETH Greenland Expedition. Progress Report 2: April 1991 to October 1992.)

Reeh, N. 1991. Parameterization of melt rate and surface temperature on the Greenland ice sheet. Polarforschung, 59 3), 1989, 113-128.

Wal, R.S.W. van de and J. Oerlemans. 1994. An energy balance model for the Greenland ice sheet. Global and Planetary Change, 9 (1-2), $115-131$.

Wal, R.S. W. van de and 11 others. In press. Mass balance measurements in the Sondre Stromfjord area in the period 1990-1994. Z. Gletscherkd. Glazialgeol.

Walraven, R. 1978. Calculating the position of the Sun. Sol. Energy, 20, 393-397.

Warren, S. G. 1982. Optical properties of snow. Rev. Geophys. Space Phys., 20 (1), $67-89$.

Weidick, A. 1984. Studies of glacier behaviour and glacier mass balance in Greenland - a review. Geogr. Ann., 66A (3), 183-195.

\section{APPENDIX}

\section{ESTIMATE OF THE EXCHANGE COEFFICIENT}

So far, direct observations of turbulent fluxes on glaciers (by eddy-correlation techniques) have been very limited (e.g. Munro, 1989; Henneken and others, 1994), and data sets are not yet adequate for a thorough verification of existing theoretical schemes (the profile method, in particular). Therefore, it seems worthwhile to use alternative methods to estimate exchange coefficients.

One such method is to calculate the total turbulent exchange as a residual in the energy balance. This requires accurate measurements of the radiation balance, the sub-surface energy flux and the amount of energy used for melting. In practice, sufficient accuracy can only be obtained over longer periods of time during which the melt process is simple (negligible sub-surface heat flux, no internal accumulation, air temperature above the melting point most of the time).

These conditions are met for three sites (4,5 and 6; Fig. 1) along the GIMEX transect, and an attempt has been made to estimate the turbulent exchange by closing the energy budget. The period considered is 10 June-25 July 1991. Data available are measured ablation, air temperature, wind speed, absorbed solar radiation, and humidity at site 4 . Some other quantities were not used because the measurement errors were considered too large.

The long-wave radiation balance is calculated using the parameterization developed by Konzelmann and others (1994). First of all, cloudiness is estimated from the difference between theoretical clear-sky global radiation and the actually observed global radiation (the result for site 5 is shown in Figure 12). Estimated cloudiness, measured air temperature and vapour pressure are then used to calculate the long-wave balance. Humidity was measured only at sites 4 and 9 . Values for sites 5 and 6 were obtained by interpolation.

Now the exchange coefficient $C$ is defined in:

$$
B=R+C\left(T_{\mathrm{a}}-T_{\mathrm{s}}\right)+C \frac{\left(L_{\mathrm{m}}+L_{\mathrm{v}}\right)}{c_{\mathrm{p}}}\left(q-q_{\mathrm{sat}}\right) .
$$

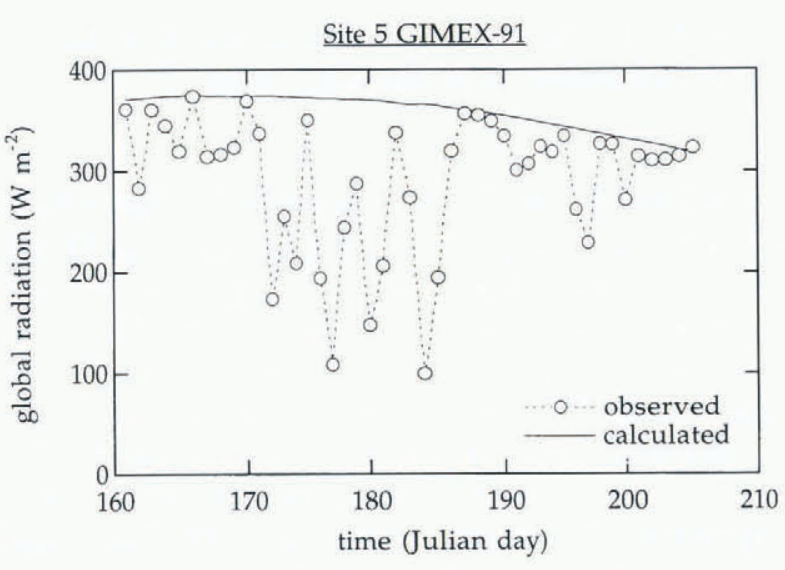

Fig. 12. Theoretical clear-sky global radiation (including the effect of water vapour and variations in surface albedo through multiple reflection between surface and atmosphere) and measured global radiation at site 5. 
Here $B$ is the energy available for melting per unit of time and area, $R$ is the net radiation, and the last two terms are the turbulent flux of enthalpy and latent heat, respectively. $C$ is the exchange coefficient (taken equal for sensible and for latent heat), $T_{\mathrm{a}}$ is air temperature, $T_{\mathrm{s}}$ is surface temperature (melting point), $L_{\mathrm{v}}$ is latent heat of vaporization, $c_{\mathrm{p}}$ is specific heat, and $q$ is specific humidity.

At the same time the mass budget is $\left(L_{\mathrm{m}}\right.$ is the heat of melting and $M$ the rate of change of mass per unit area in $\left.\mathrm{kg} \mathrm{m}^{-2} \mathrm{~s}^{-1}\right)$ :

$$
M=\text { melting }- \text { deposition } \longrightarrow \frac{B}{L_{\mathrm{m}}}=M+\frac{C}{c_{\mathrm{p}}}\left(q-q_{\mathrm{sat}}\right) .
$$

Eliminating $B$ now yields:

$$
M L_{\mathrm{m}}=R+C\left(T_{\mathrm{a}}-T_{\mathrm{s}}\right)+\frac{C}{c_{\mathrm{p}}} L_{\mathrm{v}}\left(q-q_{\mathrm{sat}}\right) .
$$

Taking the mean value over the entire period and solving for $C$ gives:

$$
C=\frac{M L_{\mathrm{m}}-\bar{R}}{\overline{T_{\mathrm{a}}-T_{\mathrm{s}}}+\frac{L_{\mathrm{v}}}{c_{\mathrm{p}}}\left(\overline{q-q_{\mathrm{sat}}}\right)} .
$$

Figure 13 shows the values for $C$ obtained in this way. In spite of the large error bars, the data suggest that the exchange coefficient decreases significantly with increasing distance from the edge of the ice sheet.

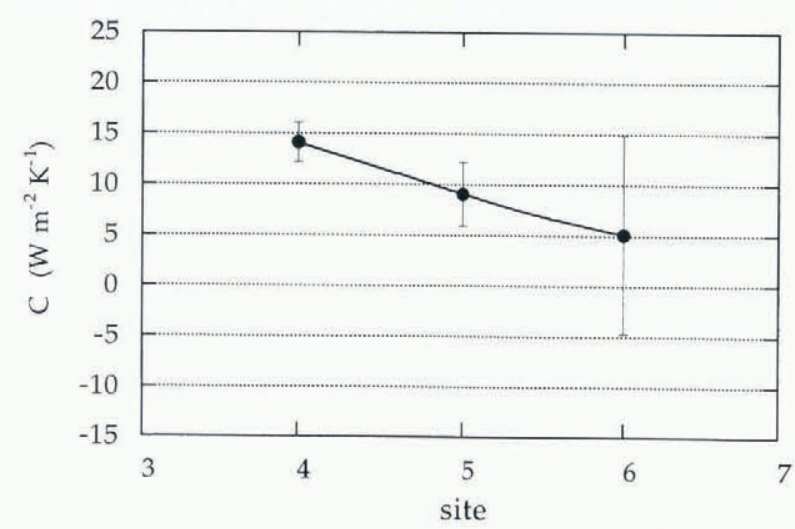

Fig. 13. Exchange coefficients calculated by closing the energy balance for sites 4, 5 and 6 . The error bars result when the uncertainty in the energy balance is assumed to be $6 \%$. This yields a very large error for site 6 , because the turbulent fluxes are small there. 